\title{
A ANÁLISE CONJUNTURAL SOBRE UNICIDADE E PLURALIDADE SINDICAL BUSCANDO A CULTURA COMO MECANISMO DA REDUÇÃO DE DANOS À CLASSE PROLETÁRIA
}

\author{
THE JOINT ANALYSIS ON UNITY AND PLURALITY SEEKING CULTURE AS \\ A MECHANISM FOR REDUCING DAMAGE TO PROLETARY CLASS
}

\author{
Ciro Coelho de Sá Beviláqua ${ }^{1}$ \\ Sarah Aguiar Sousa ${ }^{2}$
}

RESUMO: Este presente trabalho tem o objetivo de expor uma reflexão crítica acerca da unicidade e da pluralidade sindical tendo como relação direta a filiação e a participação colaborativa nos sindicatos. Sobre o prisma democrático se analisará que a coercibilidade dos detentores dos meios de produção bem como o Estado Neoliberal interferem nos sindicatos com a finalidade de miná-los e consequentemente enfraquecer as mobilizações paredistas. Por fim se exporá através do método dedutivo como aplicar uma política de redução de danos à precarização trabalhista.

Palavras-chave: Unicidade. Pluralidade. Sindicato. Proletariado. Democrácia.

ABSTRACT: This paper aims to expose a critical reflection on the uniqueness and plurality of the union, having as direct relation the affiliation and the collaborative participation in the unions. From the democratic point of view it will be analyzed that the coercibility of the holders of the means of production as well as the Neoliberal State interferes in the unions with the purpose of undermining them and consequently weakening the paredist mobilizations. Finally it will be exposed through the deductive method how to apply a policy of harm reduction to precarious labor.

Keywords: Uniqueness. Plurality. Union. Proletariat. Democracy.

\section{INTODUÇÃO}

Após as revoluções industriais que começaram na Europa em meados do século XVIII e se expandiram pelo século XIX, onde houve a troca da produção manufaturada por produções via máquinas, ocorreu a criação dos sindicatos, que nasceram na Inglaterra com o intuito de frenar a precarização da mão de obra nos setores industriais, visto que o

\footnotetext{
I Pós-graduado em Direito da Família e Sucessões pelo CERS. E-mail: cirobevilaqua@hotmail.com 2 Acadêmica do curso de Direito, décimo semestre da Faculdade Luciano Feijão. E-mail: sarahaguiarsousa@gmail.com
} 
sistema capitalista visa a maximização dos lucros em detrimento à dignidade dos proletários.

Incialmente os sindicatos foram criados de forma clandestina e reprimidos como verdadeiros terroristas, tendo que realizar suas assembleias em lugares inóspitos devido às perseguições exacerbadas por parte do Estado e dos detentores dos meios de produção, tendo vários de seus integrantes presos e até mortos. Sua função era confrontar os empregadores e o Estado para poder adquirir direitos e dignidade sem suas atividades laborais.

O primeiro evento com repercussão foi o ludismo, movimento onde os trabalhadores quebraram as máquinas fabris, depois desse movimento revolucionário o parlamento inglês aprovou uma lei dando direito à livre associação às uniões sindicais, essas associações começaram a negociar com os patrões a fim de garantir direitos.

A organização sindical constitui um direito básico à classe trabalhadora, mas cada país passa por sua própria evolução nas garantias do Direito do Trabalho, logo é preciso compreender a realidade jurídica e histórica sobre a qual cada sociedade fora construída. Para buscar a evolução dos direitos trabalhistas deve-se atentar aos dogmas e costumes de tal sociedade que tem seus preceitos deontológicos, com o intuito de dirimir as desigualdades e fortalecer a dignidade da pessoa humana.

Portanto é preciso compreender a conjuntura jurídica e política sobre a qual a sociedade fora construída e na qual vive até os dias de hoje, para que tal disputa não se torne anacrônica ou sem sentido, para isso é necessário repensar esses velhos dogmas e buscar uma forma de compreender os fenômenos jurídicos e políticos e suas consequentes repercussões ao mundo dos fatos.

Desde a promulgação da Constituição Brasileira de 1988 é notória as controversas acerca da estrutura sindical, essa que foi fixada pela nossa magna carta, tendo como foco principal a determinação legal quanto à unicidade, ficando evidente a intervenção estatal e o seu favorecimento as centrais sindicais já existentes, assim criando uma simbiose entre Estado e sindicatos, contrariando o real sentido da instituição que deveria servir como interlocutor dos anseios dos proletariados.

A conjuntura democrática no Brasil sempre teve suas raízes fincadas em solo infértil, trazendo consigo traços de suas "heranças malditas", assim como sucinta Sérgio 
Buarque de Hollanda (1995, p.r6o) “A democracia no Brasil foi sempre um lamentável malentendido". Como pode citar a positivação da unicidade sindical no ordenamento jurídico, mostra-se notoriamente axiológica aos períodos autoritários do qual serviu como base a essa normatização hoje presente.

A função dos sindicatos é a conscientização dos trabalhadores sobre o prisma da "consciência de classe" atrelando a esse tema as próprias lutas contra o sistema hegemônico e aos detentores dos meios de produção, assim tornando-se em uma unidade. Essa norma delimitadora chamada unicidade, mitiga o direito à liberdade sindical, pois se faz exaurir a representatividade material e dando um ar de representação meramente formal, fazendo com que os dirigentes não deem o devido "feedback" aos participantes de sua determinada categoria.

No tocante às organizações sindicais, a OIT, que é um órgão da ONU, em sua convenção de número 87 , datada de 04 de julho de 1950 , explicita como devem ser as estruturas sindicais, afim de haver uma equidade entre os países sobre a égide da legislação trabalhista fundada sobre um prisma cosmopolita, que para Immanuel Kant (2013.p.137.) "O Direito cosmopolita deve ser limitado às condições da hospitalidade universal", corroborando com Kant, para Norberto Bobbio (1995, p. I64.) o direito cosmopolita é:

\footnotetext{
Uma seção do direito diversa do direito internacional (...), pois enquanto o direito internacional regula as relações entre os Estados, e o direito interno regula as relações entre o Estado e os próprios cidadãos, o direito cosmopolita regula as relações entre um Estado e os cidadãos dos outros Estados (ou seja, os estrangeiros).
}

Antonio Gramsci vê que instrumentos de luta de classes tem potencial decisivo junto ao poder estatal, logo os sindicatos devem ser coordenados e direcionados por princípios basilares de um partido que represente a coletividade, sendo que este partido tenha uma efetiva participação dos proletários. Tão logo para ratificar essa ideia, Gramsci (1976, p.30) relata:

O Estado socialista já existe em potência nas instituições da vida social características da classe trabalhadora explorada. Interligar estas instituições, coordená-las e subordiná-las numa hierarquia de competências e poderes altamente centralizados, respeitando, porém, as indispensáveis autonomias e articulações, significa criar aqui e agora uma verdadeira e representativa democracia operária, eficaz e efetivamente oposta ao Estado burguês, e já preparada para substituir em todas as suas funções essenciais de gestão e controle do patrimônio nacional. 
Para consolidar os partidos e sindicatos em uma democracia substancial é necessário a participação ativa dos integrantes e a liberdade de escolha dos mesmos a outros sindicatos, criando a pluralidade sindical. Doravante para se preservar esta pluralidade sem pender o fiel da balança a um dos lados, o filósofo americano John Rawls (2016) postulou a teoria do "véu da ignorância, também chamada de posição original" onde as pessoas sobre esse véu, escolheriam os princípios de justiça como produto consensual. Aqueles que consentirem na posição original, são seres possuídos de razão e desinteresse, assim não podendo dirimir nem escolher um princípio, logo não privilegia a um e nem ao outro.

Por fim para Amauri Mascado Nascimento (20II, p.1232) fala que "a intervenção e a interferência do Estado no movimento sindical, invalida, também, a sua naturalidade na medida em que o submete aos modelos estabelecidos pelo Estado em detrimento da sua livre organização e ação". Seguindo como baliza a Constituição Federal de 1988 que demonstra que a liberdade de associação (art. $5^{\circ}$, incisos XVII a XXI) está assegurada no artigo 8ㅁ, "caput", e inciso V. Assim a intervenção do Estado de forma direta ou indireta desvirtua o cerne da organização sindical.

\section{O INSTITUTO DA UNICIDADE SINDICAL}

A unicidade sindical representa o impedimento ao fracionamento dos sindicatos, impedindo o estabelecimento de mais de um sindicato para determinada categoria em uma mesma base territorial, sendo essa base o município. Tendo esse impedimento respaldado na própria constituição.

Para melhor compreensão sobre o instituto da unicidade sindical é melhor voltarmos à constituinte de 1988 , onde houve uma forte intervenção dos sindicatos patronais e de empregados aos formuladores da nova constituição, estes que tinham a finalidade de inserir no novo texto o instituto da unicidade como base para a formulação sindical. É de notório conhecimento que antes da reforma trabalhista imposta pela Lei № 13.467, de 2017, havia o chamado imposto sindical, onde em parcela única no mês de maio, havia o recolhimento de um dia de serviço que era destinada à sua central sindical.

Com o intuito de manter esse benefício compulsório as centrais sindicais fizeram de tudo para que o legislador inserisse no texto da nova constituição as diretrizes para se 
positivar tal recolhimento, logo fortalecendo a unicidade, alegando que se fosse adotado a pluralidade e o efeito "inter partes" haveria um exaurimento da defesa aos trabalhadores que não estivessem filiados. Para isso Oliveira Viana (1993, p.12) critica a pluralidade:

Agindo exclusivamente como representante legal do seu corpo de associados, isto é, de uma fração da categoria e não da categoria toda; e, neste caso, os interesses $\mathrm{da}$ categoria, considerada como uma totalidade, ficariam sem representação específica, o que importaria dificultar ou mesmo impossibilitar a obra tutelar do Estado, desde que ao Estado só seria lícito agir para proteger os interesses gerais da categoria toda e não os interesses desta ou daquela associação profissional, isto é, desta ou daquela fração privatizada da categoria.

Por outro lado, a instrumentalização em um órgão oficial traria um entrave a pluralidade de pensamentos e ideologias trazendo uma inflexibilidade às relações negociais, visto que sendo o sindicato um órgão único estaria implantado um monopólio e de forma unilateral o sindicato monopolizador não representaria a sua totalidade e tão logo não seria um instrumento da consciência coletiva. Com isso Gallart Folch (1932, p.r29) fala:

À luz de um critério puramente racionalista, prescindindo-se das considerações de vitalismo social, o sindicato oficial obrigatório apresenta, fora de dúvida, uma enorme superioridade sobre o sindicato voluntário. O sindicato oficial estaria integrado por todos os trabalhadores da profissão; seus dirigentes, por eles eleitos, representariam com autenticidade a mão-de-obra dessa especialidade produtora e, portanto, seriam os únicos mandatários autorizados para negociar com o capital o regime de trabalho a que essa mão-de-obra teria de se sujeitar. Mas esse mecanismo, teoricamente tão perfeito, não teria um bom rendimento funcional. $\mathrm{O}$ sindicato deixaria de ser uma manifestação viva da consciência coletiva para se converter num frio organismo oficial. $O$ sindicato oficial, privado da adesão popular, seria um instrumento inútil. Negociador de um pacto coletivo de condições de trabalho, careceria de força moral para o impor a seus próprios sindicalizados.

A própria classe operária quer um sindicato forte e ativo, mas ao mesmo tempo teme pela inércia reativa dos seus trabalhadores, pois há uma influência hegemônica da classe dominante implícita no amago da classe proletária, fazendo que a mesma fique silente diante das tomadas de decisões. Assim caberiam aos sindicatos tomarem as rédeas e aplicar como diria Friedrich Nietzsche (2008)“a vontade de poder ou potência”, que em outras palavras, o esforço para alcançar o ideal desejado. Como explicita Coutinho (I99ı, p. I05-106).

Para Gramsci, a possibilidade da construção de uma nova hegemonia está na capacidade de formação de uma vontade coletiva revolucionária dirigida pela classe operária. Nessa construção, chama a atenção para a centralidade das observações da necessidade da superação dos movimentos espontâneos pela direção política consciente, ou seja, por "uma síntese político-intelectual que 
supere os elementos de corporativismo e transforme tais movimentos em algo homogêneo, universalizante, capaz de ação eficaz e duradoura.

Por fim a estrutura sindical brasileira é baseada ainda no regime corporativo de Mussolini, em que só é possível o reconhecimento de um único sindicato [...]. Um único sindicato era mais fácil de ser controlado, tornando-se obediente. (MARTINS, 2006, p.699).

\section{DA PLURALIDADE SINDICAL}

No ano de 1948 a Organização Internacional do Trabalho - OIT aprovou a convenção de número 87 sendo posta em prática em 1950, essa convecção tratava da liberdade sindical e da proteção do direito à sindicalização, tendo como princípio basilar a pluralidade sindical, que é o direito à liberdade de escolha, onde o trabalhador pode escolher a qual instituição sindical se adequa mais aos seus preceitos ideológicos.

A liberdade sindical está correlacionada à liberdade de escolha, logo o Estado não pode intervir com a finalidade de exaurir este avanço democrático. A luta de classes deve está fincada em todo movimento sindical, pois é através da inserção da consciência de classe que o proletariado tem conhecimento de seu lugar de fala, "A luta entre capitalista e assalariado começa com a própria relação capital. Ela se agita por todo período manufatureiro". (MARX,1996, p. 59).

Pegando como base a pluralidade sindical Wilson de Souza Campos Batalha (1994, p. 83) assevera que:

Pluralidade sindical consiste na permissão de várias entidades, na mesma base territorial, exercerem a representação da mesma categoria, disputando-se qual o sindicato mais representativo, ou as condições para uma participação proporcional na representação da categoria.

Havendo a possibilidade de escolher qual sindicato melhor representaria certa categoria, os dirigentes sindicais iriam dar o "feedback" necessário como resposta aos seus filiados, fazendo uma interação entre sindicato e sindicalizado, passando a ter um envolvimento maior dos próprios associados com as diretrizes e decisões que outrora eram tomadas por quem estava à frente dos sindicatos. Logo o envolvimento na práxis dos sindicalizados consolidaria o próprio sindicato como uma instituição plenamente democrática. 
Para se ter um entrelace maior entre os sindicalizados e os sindicatos seriam necessários além do envolvimento nos rumos da luta de classe um retorno de exclusividade nas relações entre empregador e empregado. Para se ter uma maior solidez, os efeitos das negociações devem ser "inter partes", logo só aqueles que estiverem com suas contribuições em dias teriam as garantias e conquistas derivadas das advindas negociações.

Porém surge uma indagação, como entre uma gama de possibilidades de diferentes sindicatos, qual teria a legitimidade para poder negociar com a empresa? $O$ simples fato de ter vários sindicatos não ocasiona um enfraquecimento de direito da categoria representada, uma vez que esses mesmos sindicatos poderiam se unir para atuar em conjunto na persecução dos direitos pleiteados. Assim criando a unidade sindical.

Sobre uma outra ótica sobre a sindicalização a tentar equilibrar a unicidade e a pluralidade, Alfredo J. Ruprecht (1995, p.) alega que:

\begin{abstract}
Tem suas vantagens e seus inconvenientes. Todos os trabalhadores unidos têm maior peso e, portanto, mais poder de ter atendidas suas reivindicações do que quando não o estão. Se a obrigatoriedade vem junto com a pluralidade de sindicatos, há mais respeito à vontade dos trabalhadores, já que podem constituir outro sindicato se não estão de acordo com ele ou com os existentes. O que reduz a liberdade sindical é o direito de não se filiar se não se deseja fazêlo.

O problema da filiação obrigatória mais grave é no que tange à existência de um sindicato único. Aqui não há nenhum tipo de liberdade sindical; nada é deixado à vontade do indivíduo. A única coisa que se pode fazer para diminuir a gravidade da lesão da liberdade sindical é a introdução dos princípios da democracia moderna, isto é, dar espaço às minorias na direção e na administração. De qualquer maneira, os já citados postulados da liberdade sindical sofrem nesse caso gravíssimas deteriorações que, praticamente, anulam sua existência.
\end{abstract}

A politização dos filiados e a participação ativa faz com que a pluralidade sindical busque dentre os sindicatos existentes o que melhor representa a coletividade e os interesses de seus filiados, assim fazendo uma seleção natural dentre os sindicatos que não derem o seu melhor para poder representar a quem deveria representar. Logo a quebra da unicidade sindical seria também a quebra da hegemonia burguesa sobre o mecanismo engessado que em tese deveria ser a representação da classe proletária.

Quando a pluralidade evolui a unidade sindical chega um nível avançado em sua representatividade, quando se sai do mundo das ideias e se adentra à práxis, seu alcance acaba se estendendo a outros campos de abrangência e se ramificando em todo âmbito estatal, logo quando há a união com a finalidade em comum seus integrantes pouco a 
pouco se proliferam e a representatividade estará presente em todos os setores do Estado e tão logo a ideia se tornará o próprio Estado.

\section{A CULTURA COMO MECANISMO DE REDUÇÃO DE DANOS TRABALHISTAS}

Em um mundo guiado pela política de mercado, a ética e a valoração ao ser humano é colocado em segundo plano. Vivemos em estado de latência, o ser silente está cada vez mais aceitável no cenário global, por isso hoje mais do que nunca, é necessária a luta e a conscientização de sua condição como força motriz no mundo globalizado. Paulo Freire (1996, p.I44-I45) diz:

O discurso da globalização que fala da ética esconde, porém, que a sua é a ética do mercado e não a ética universal do ser humano, pela qual devemos lutar bravamente se optamos, na verdade, por um mundo de gente. [...] Há um século e meio Marx e Engels gritavam em favor da união das classes trabalhadoras do mundo contra sua espoliação. Agora, necessária e urgente se fazem a união e a rebelião das gentes contra a ameaça que nos atinge, a negação de nós mesmos como seres humanos submetidos à "fereza" da ética do mercado.

Tendo como base que existem duas classes a proletária e a burguesa, György Lukács (2003, p. I43) explica que:

A burguesia e o proletariado são as duas únicas classes puras da sociedade, isto é, apenas a existência e a evolução dessas classes se baseiam exclusivamente na evolução do processo moderno de produção e não se pode imaginar um plano de organização da sociedade em seu conjunto senão a partir de suas condições de existência.

Sabendo que a lógica de mercado é o dualismo entre burguesia e trabalhadores, também se sabe que a união das organizações se cria a unidade, assim essa união de ideias é pra Gramsci (1976) o "centro unitário de cultura" cujo objetivo é a elaboração unitária de uma consciência coletiva, ou como diria Immanuel Kant (2009, p.215) "um imperativo categórico", tendo como finalidade a superação de um senso comum outrora estipulado pela classe hegemônica, nesse mesmo enfoque elenca-se a atuação de intelectuais nas mídias e nas escolas para haver o confronto ideológico e para se aplicar a filosofia da práxis.

Por fim o princípio da unidade ou princípio unitário está relacionado à luta pela igualdade social e a superação das divisões de classes, buscando a inserção da cultura e a consciência de classe, com o intuito de compreender o seu lugar como peça fundamental no sistema produtivo e econômico vigente. 


\section{CONCLUSÃO}

Pode-se constatar que há um debate até hoje sem consenso, sobre os institutos da pluralidade e da unicidade sindical, ambos defendem suas bandeiras com as suas verdades, porém o que não se pode contestar é que o ser humano é um ser plural, advindo de desejos e vontades, se ramificando nas mais diversas direções políticas, ideológicas entre outras vertentes.

A evolução humana se dá através da luta constante por direitos e melhorias, começando propriamente dito, sobre o prisma trabalhista, nas revoluções industriais ao redor de todo globo, em especial na Inglaterra do século XVIII, assim buscando sempre mudar a conjuntura jurídica e política da época em que se vive, visando uma melhoria às condições trabalhistas.

Ainda sobre o cenário mundial, foram criados alguns órgãos e feitos alguns tratados e acordos de ampla adesão, com o aparente intuito de dar uma isonomia às relações de emprego e trabalho entres os países colaboradores, a ONU e a OIT são dois exemplos de instituições que tem o interesse cosmopolitano de agregar valor à dignidade da pessoa humana bem como estabelecer diretrizes, que em tese, devem ser seguidas por todos aqueles que fizerem parte.

No Brasil foi formalizada na Constituição Federal de 1988 o instituto da unicidade sindical, este que rege apenas um sindicato em uma mesma base territorial, mostrando assim como o Estado em especial o Neoliberal e as grandes corporações, intervém de forma abrupta na conjuntura política, visando a maior influência e maior facilidade de domínio hegemônico sobre a instituição sindicato.

A luta pelo direito democrático de poder escolher qual sindicato melhor o representa, é um calvário percorrido já a algum tempo. A pluralidade sindical, busca maximizar às minorias, dando lugar de fala e oportunidade de inserção destas na luta por melhores condições. A liberdade de escolha agregada à práxis leva ao entendimento unitário ou unidade da classe trabalhadora, assim seria a união desta contra os desmandos das classes hegemonicamente superioras.

Por fim se busca estabelecer quais mecanismos de redução de danos podem dirimir a coercibilidade da unicidade e balancear com a pluralidade os direitos e garantias da classe trabalhadora. Pois em uma sociedade guiada pelo capitalismo, a luta de classes deve ser 
constante pois como disse Simone de Beauvoir (1967, p.21) "Nunca se esqueça que basta uma crise política, econômica ou religiosa para que os direitos das mulheres sejam questionados. Esses direitos não são permanentes. Você terá que manter-se vigilante durante toda a sua vida." Assim como são os "direitos das mulheres" são os direitos trabalhistas.

\section{REFERENCIAL BIBLIOGRÁFICO}

COUTINHO, C. N. Gramsci: um estudo sobre seu pensamento político. Rio de Janeiro: Campus, I99I.

CUOCO, V. Saggio storico sulla rivoluzione di Napoli. Milano, Rizzoli editore,1999.

BATALHA, W.S.C. Sindicatos - Sindicalismo. 2 ed. São Paulo - SP: LTr Editora, 1994.

BOBBIO, Norberto. Direito e Estado no pensamento de Emanuel Kant. $3^{\text {a }}$ edição. Trad. Alfredo Fait. Brasília: Editora UNB, 1995.

FOLCH, G. Los convenios colectivos de condiciones de trabajo en la doctrina y en las legislaciones extranjeras y española, Barcelona, 1932.

FREIRE, Paulo. Pedagogia da Autonomia: saberes necessários à prática educativa. 5. ed. Rio de Janeiro: Paz e Terra, 1996.

GRAMSCI, Antonio. Sobre democracia operaria e outros textos. Biblioteca Ulmeiro. n.4. Lisboa: Ulmeiro. 1976.

HOLANDA, S.B. Raízes do Brasil. São Paulo: Cia das Letras, 1995.

KANT, Immanuel. À Paz Perpétua, um Projeto Filosófico, Editora: WMF Martins Fontes; Edição: 2ª ${ }^{\underline{a}}, 2013$.

KANT, Immanuel. Fundamentação da Metafísica dos Costumes. Tradução, introdução e notas por Guido de Almeida. São Paulo: Discurso Editorial: Barcarola, 2009.

MARTINS, Sergio Pinto. Direito do trabalho. 22. ed. São Paulo: Atlas, 2006.

MARX, Karl. O CAPITAL. Crítica da Economia Política. São Paulo: Nova Cultural, Ltda, 1996.

NIETZSCHE, F. Vontade De Poder. Editora: Contraponto; Edição: Iํ‥ 2008.

NASCIMENTO, A.M. Curso de Direito do Trabalho: História e teoria geral do direito do trabalho, relações individuais e coletivas do trabalho. $26^{\mathrm{a}}$ ed. - São Paulo: Saraiva, 2011 . 
RUPRECHT, Alfredo J. Relações Coletivas de Trabalho. I⿳ㅗㄹ ed., São Paulo. LTr Editora, I995.

BEAUVOIR, Simone de. O Segundo Sexo: a experiência da vida. Tradução de Sérgio Milliet.2 ed. Paris, Gallimard,1967.

VIANA, O. Problemas de Direito Sindical. Rio de Janeiro, Direito Coletivo do Trabalho - Manual de Direito do Trabalho - Volume III, 3ae ed., São Paulo, Editora LTr, 1993. 